\title{
ANÁLISE DO CONTEÚDO DAS LEISHMANIOSES EM LIVROS DIDÁTICOS DE CIÊNCIAS E BIOLOGIA INDICADOS PELO PROGRAMA NACIONAL DE LIVROS DIDÁTICOS (2008/2009)
}

\author{
An analysis on the content of the Leishmaniasis in science \\ and biology books indicated by the Brazilian Didatic Book \\ National Program (2008/2009)
}

\author{
Viviane Helena de França ${ }^{1}$ \\ Carina Margonari ${ }^{2}$ \\ Virgínia Torres Schall ${ }^{3}$
}

\begin{abstract}
Resumo: Realizou-se análise do conteúdo das leishmanioses em livros didáticos de ciências e biologia, indicados pelo Programa Nacional do Livro Didático - PNLD/2008 e PNLEM/2009. Os critérios de análise reportaram aos seguintes temas: compromisso social, relação entre saúde e ambiente, qualidade científica, correção dos conceitos e ilustrações. Foram analisados sete dos 13 livros de ciências indicados pelo PNLD/2008 e todos os nove livros de biologia do PNLEM/2009; esses foram adotados em escolas públicas brasileiras no período letivo de 2008 a 2011. Todos os livros apresentaram incorreções científicas, linguagem descontextualizada e lacunas de informação, desfavorecendo a construção do conhecimento e não estabelecendo relações com aspectos históricos, socioculturais e econômicos associados às doenças. Tais constatações, somadas a achados semelhantes na literatura, levam à proposição de que o tema saúde deveria ter tratamento em separado, constituindo-se como volume específico, considerando a sua transversalidade e potencial para estabelecer diálogos para uma formação cidadã.
\end{abstract}

Palavras-chave: Leishmanioses. Educação em saúde. Livro didático. Ensino de ciências.

\begin{abstract}
The content related to Leishmaniasis in science and biology textbooks indicated by the Brazilian Didactic Book National Program - PNLD/2008 and PNLEM/2009 - was analyzed. The analysis criteria reported to the social commitment, to the relation between health and environment, to the scientific quality, to the correction of concepts and illustrations. Seven of the 13 science books indicated by the PNLD/2008 and all of the nine PNLEM/2009 biology books were analyzed; these were adopted in Brazilian public schools from 2008 to 2011. All books presented scientific inaccuracies, decontextualized language and information gaps, making it unfavorable for teachers and students to construct the knowledge and establish relationships with historical, sociocultural and economic issues related to the diseases analyzed. These findings associated with similar data from the literature leads to the proposition that the health issue should be treated separately, being as specific volume, considering its transversality and potential to establish a dialogue for a citizenship education.
\end{abstract}

Keywords: Leishmaniasis. Health education. Didactic book. Science education.

\footnotetext{
${ }^{1}$ Graduada em Enfermagem, mestre e doutoranda em Ciências da Saúde. Laboratório de Educação em Saúde e Ambiente (LAESA), Centro de Pesquisa René Rachou (CPqRR), Fundação Oswaldo Cruz (Fiocruz). Belo Horizonte, MG, Brasil. < vivianehfranca@cpqrr.fiocruz.br>. Apoio: CNPq e FAPEMIG.

${ }^{2}$ Graduada em Ciências Biológicas, mestre em Biologia Celular e Molecular, pós-doutora em Biologia Parasitária. Pesquisadora, LAESA, CPqRR, Fiocruz. Belo Horizonte, MG, Brasil. <margonari@cpqrr.fiocruz.br>

${ }^{3}$ Graduada em Psicologia, mestre em Neurofisiologia e doutora em Educação. Pesquisadora, LAESA, CPqRR, Fiocruz. Belo Horizonte, MG, Brasil.<vtschall@cpqrr.fiocruz.br>

${ }^{1}$ Av. Augusto de Lima, 1.715

Barro Preto - Belo Horizonte, MG

30.190-002. 
França, V. H.; Margonari, C.; Schall, V. T.

\section{Introdução}

Dentre as doenças parasitárias que prevalecem no Brasil - acometendo indivíduos em grande proporção, e que merecem a atenção de gestores, profissionais de saúde, pesquisadores, educadores e população - encontram-se as leishmanioses. Os dados do Sistema de Informação de Agravos de Notificação (SINAN) - Ministério da Saúde (MS) revelam que tem ocorrido no Brasil, nos últimos anos, um número alarmante de casos de Leishmaniose Tegumentar Americana (LTA) e Leishmaniose Visceral (LV). Em 2008, 2009 e 2010, foram, respectivamente, 21.674, 23.122 e 21.866 notificações pela LTA; 3.990, 3.892 e 3.643 notificações pela LV. Nesse período, a LTA foi notificada em todos os estados brasileiros, e a LV em 23 desses (BRASIL, 2011). Essas doenças, atualmente, configuram-se, no país, como graves problemas de saúde pública, ocasionando sérios prejuízos sociais aos portadores.

Os programas de controle das leishmanioses no Brasil priorizam como ações: o tratamento de doentes, a eutanásia de cães infectados pelo parasita, e a aplicação de inseticidas em áreas endêmicas, para o controle de vetores (BORGES et al., 2008). É dada pouca atenção à educação em saúde para o enfrentamento das enfermidades.

Estudos de Reis et al. (2006), Borges et al. (2008), abordando os conhecimentos e representações sociais sobre a LTA e LV pela população brasileira, demonstram que a mesma é desinformada ou tem informações superficiais sobre as doenças. É comum a população não saber identificar o vetor e seus criadouros, reservatórios, medidas de prevenção, e confundir a LTA e LV com Dengue e Leptospirose (REIS et al., 2006; BORGES et al., 2008).

Outras pesquisas no Brasil, referentes à análise de materiais informativos e educativos sobre as leishmanioses, verificaram que esses veiculam erros conceituais, dificultando sua prevenção. Pimenta, Leandro e Schall (2006, p. 106) afirmam que, nesses materiais, "na tentativa de simplificar as informações para o público leigo faz com que elas sejam, na verdade, banalizadas e desqualificadas". Luz et al. (2003) analisaram materiais informativos abordando as leishmanioses e observaram que esses multiplicam preconceitos em relação aos pacientes e conceitos distorcidos de vetores e reservatórios, prejudicando as ações profiláticas.

A educação em saúde é uma estratégia indispensável no processo de prevenção e controle das doenças endêmicas; contudo, deve ser coerente, respaldada em conhecimentos científicos, adequada à população e seu contexto, e ocorrer de modo participativo, incluindo todos os segmentos da comunidade.

Alguns autores que abordaram a educação em saúde sobre as leishmanioses junto a alunos e professores do Ensino Básico demonstraram que esse grupo constitui agente multiplicador potencial de conhecimentos em nível comunitário e pode auxiliar na prevenção das doenças (UCHÔA et al., 2004; MAGALHÃES et al., 2009).

Nas escolas de Ensino Básico, as disciplinas de ciências e biologia configuram-se como espaços importantes de educação em saúde. Durante essas aulas, são reelaborados conceitos e compartilhadas experiências relacionadas à qualidade de vida, promoção da saúde e prevenção de doenças. Os livros didáticos de ciências e biologia são os recursos pedagógicos mais usuais e valorizados por professores e alunos, sendo importantes na divulgação de informações junto aos mesmos. Quando dotados de conteúdos científicos corretos, transpostos para uma linguagem apropriada à faixa etária dos escolares, associados às reflexões sociopolíticas 
e culturais e estímulo as ações participativas em saúde, podem contribuir para que educadores e educandos apreendam conhecimentos preventivos adequados em relação às doenças.

Fracalanza, Amaral e Gouveia (1986) afirmam que a escolha apropriada de livros didáticos é um problema sério a ser pensado pelas instituições vinculadas ao ensino. Para muitos brasileiros, esses materiais representam o único texto com que interagem ao longo da vida, devido ao seu baixo poder aquisitivo e a sua alta taxa de evasão escolar. Schall e Diniz (2001) destacam que os materiais informativos e livros didáticos, produzidos no Brasil, abordando as doenças, geralmente, têm sido elaborados como cópias uns dos outros, reproduzindo erros durante algumas décadas. Fracalanza, Amaral e Gouveia (1986) descrevem que, além de erros conceituais, é comum os livros didáticos apresentarem lacunas nas informações quanto aos conteúdos abordados. Assim, tais materiais devem ser elaborados pautando-se em critérios bem definidos de qualidade e cientificidade (LUZ et al., 2003).

Desde 1929, existe, no Brasil, uma preocupação do governo com a distribuição de obras didáticas para estudantes da rede pública; mas, foi em 1985 que se deu a criação do Programa Nacional do Livro Didático (PNLD), e, em 1993, a Resolução nº do Fundo Nacional de Desenvolvimento da Educação (FNDE) estabeleceu os recursos para sua aquisição e distribuição nas escolas públicas. Em 1996, o Ministério da Educação (MEC) iniciou, efetivamente, o processo de avaliação pedagógica desses materiais, com o objetivo de fornecer, aos estudantes do Ensino Fundamental, livros didáticos de qualidade. Em 2003, o MEC implantou o Programa Nacional do Livro para o Ensino Médio (PNLEM) (BRASIL, 2010).

Por meio desses programas, são realizadas a compra e a distribuição dos livros didáticos para as escolas públicas e, também, a análise criteriosa de sua qualidade em relação a cada disciplina, avaliando-se o material quanto à estrutura, conhecimentos e conceitos, linguagem, ilustração, proposta pedagógica, orientação à pesquisa, adequação ao público-alvo, ética e cidadania. Essa análise é realizada por equipes formadas por professores universitários e da rede pública de ensino de várias regiões do país, constituídas por instituições de Educação Superior públicas. Diante dos livros selecionados como adequados pelo PNLD e PNLEM, os professores das escolas públicas escolhem qual será adotado para os próximos três anos letivos (BRASIL, 2007, 2008).

Schall (2010) pondera que, apesar das análises criteriosas realizadas pelo MEC e da melhora progressiva que vem ocorrendo nos livros didáticos no Brasil, esses ainda apresentam conteúdos e ilustrações inadequados ou insuficientes, ênfase em memorização mais do que reflexões sobre saúde, sociedade e qualidade de vida, estando distantes da realidade dos alunos.

O presente estudo teve por objetivo analisar a qualidade científica e o compromisso social dos livros didáticos de ciências e biologia no que se refere ao conteúdo das leishmanioses, verificando como as doenças aparecem em tais materiais, de modo a permitirem a construção de um conhecimento relevante para a vida dos alunos. Para tal foram considerados livros de ciências das séries finais do Ensino Fundamental $\left(5^{\mathrm{a}}\right.$ a $8^{\mathrm{a}}$ série ou $6^{\circ}$ ao $9^{\circ}$ ano), indicados pelo Catálogo PNLD 2008 (BRASIL, 2007), para o período letivo de 2008 a 2010; e, também, livros de biologia do Ensino Médio indicados pelo Catálogo PNLEM 2009 (BRASIL, 2008), para os anos letivos de 2009 a 2011. Esses livros têm sido utilizados em escolas públicas de Ensino Básico de todo o Brasil, e foram coletados em instituições de Minas Gerais. 
França, V. H.; Margonari, C.; Schall, V. T.

\section{Metodologia}

Realizou-se um levantamento de livros didáticos de ciências (das séries finais do Ensino Fundamental) avaliados e indicados pelo Catálogo PNLD 2008 (BRASIL, 2007). Com base nesse levantamento, foram selecionados todos os 13 livros de ciências indicados, e verificados, dentre esses, quais contemplavam o tema das leishmanioses: LTA e LV.

Em relação aos livros de ciências, apenas sete dos 13 indicados pelo PNLD 2008 abordaram a temática e foram analisados (Quadro 1). Dentre os 13 indicados, 6 foram excluídos - 4 por não descreverem sobre as doenças e 2 por apenas citarem a "Leishmaniose" como uma enfermidade causada por protozoários, sem apresentarem explicações sobre a mesma.

Do mesmo modo, foi realizado um levantamento dos livros didáticos de biologia avaliados e indicados pelo Catálogo PNLEM 2009 (BRASIL, 2008); sendo selecionados e analisados todos os 9 livros indicados, por contemplarem a temática (Quadro 2).

Os critérios de análise dos livros didáticos basearam-se em artigos já publicados de Luz et al. (2003), Schall e Diniz (2001), Schall (2010), e reportaram a qualidade dos conceitos e definições sobre as leishmanioses. Os livros foram analisados quanto à localização do conteúdo nos capítulos, se essa favorece a compreensão dos leitores; cientificidade e correção dos conceitos; adequação da linguagem à faixa etária dos escolares, ao seu contexto geográfico e socioeconômico, considerando a relação intrínseca existente entre saúde e ambiente. Foram analisadas, ainda, as ilustrações referentes às doenças quanto à clareza, cientificidade, representação adequada em escalas e coerência em relação aos respectivos textos. A análise por esses critérios foi realizada seguindo os subtemas: tipos clínicos das leishmanioses, agente etiológico, vetor, reservatórios, manifestações clínicas dessas, tratamento, medidas de prevenção e controle individuais e coletivas, classificando-os nas categorias informações corretas, errôneas, incompletas ou ausência de informações (não citou o subtema).

Quadro 1. Livros didáticos de ciências indicados pelo PNLD 2008, analisados no presente estudo.

\begin{tabular}{|c|c|c|c|c|}
\hline Autores & Título do livro & SérielAno & Editora/ Cidade & Ano \\
\hline $\begin{array}{l}\text { Silvia Bortolozzo e } \\
\text { Suzana Maluhy }\end{array}$ & Série Link da Ciência & $\begin{array}{l}6^{\mathrm{a}} \text { série } \\
7^{0} \text { ano }\end{array}$ & $\begin{array}{l}\text { Escala educacional, } \\
\text { São Paulo }\end{array}$ & 2005 \\
\hline $\begin{array}{l}\text { Carlos Barros e } \\
\text { Wilson Paulino }\end{array}$ & Ciências: os seres vivos & $\begin{array}{l}6^{\mathrm{a}} \text { série } \\
7^{\circ} \text { ano }\end{array}$ & Ática, São Paulo & 2006 \\
\hline Fernando Gewandsznajder & Ciências: a vida na Terra & $\begin{array}{l}6^{\mathrm{a}} \text { série } \\
7^{0} \text { ano }\end{array}$ & Ática, São Paulo & 2006 \\
\hline Maria Andrade et al. & $\begin{array}{l}\text { Ciência e vida: seres vivos, } \\
\text { funções vitais e energia }\end{array}$ & $\begin{array}{l}6^{\mathrm{a}} \text { série } \\
7^{0} \text { ano }\end{array}$ & $\begin{array}{l}\text { Dimensão, Belo } \\
\text { Horizonte }\end{array}$ & 2006 \\
\hline $\begin{array}{l}\text { Demétrio Gowdak e } \\
\text { Eduardo Martins }\end{array}$ & Ciências: novo Pensar & $\begin{array}{l}5^{\mathrm{a}} \text { série } \\
6^{\circ} \text { ano }\end{array}$ & FTD, São Paulo & 2006 \\
\hline Alice Costa & Ciências e interação & $\begin{array}{l}6^{\mathrm{a}} \text { série } \\
7^{\circ} \text { ano }\end{array}$ & Positivo, Curitiba & 2006 \\
\hline Selma Braga et al. & $\begin{array}{l}\text { Construindo Consciências: } \\
\text { Ciências }\end{array}$ & $\begin{array}{l}5^{\mathrm{a}} \text { série } \\
6^{\circ} \text { ano }\end{array}$ & Scipione, São Paulo & 2006 \\
\hline
\end{tabular}

Fonte: Guia de livros didáticos PNLD 2008: Ciências (Brasil, 2007). 
Análise do conteúdo das leishmanioses ...

Quadro 2. Livros didáticos de biologia indicados pelo PNLEM 2009, analisados no presente estudo.

\begin{tabular}{|c|c|c|c|c|}
\hline Autores & Título do livro & Série & Editora/ Cidade & Ano \\
\hline $\begin{array}{l}\text { Sergio Linhares e } \\
\text { Fernando Gewandsznajder }\end{array}$ & Biologia: volume único & Ensino Médio & Ática,São Paulo & 2005 \\
\hline $\begin{array}{l}\text { José Arnaldo Favaretto e } \\
\text { Clarinda Mercadante }\end{array}$ & Biologia: volume único & Ensino Médio & Moderna, São Paulo & 2005 \\
\hline J. Laurence & Biologia: volume único & Ensino Médio & $\begin{array}{l}\text { Nova geração,São } \\
\text { Paulo }\end{array}$ & 2005 \\
\hline $\begin{array}{l}\text { César Silva Júnior e } \\
\text { Sezar Sasson }\end{array}$ & $\begin{array}{l}\text { Biologia, volume } 2 \text { : seres } \\
\text { vivos/estrutura e função }\end{array}$ & $2^{\mathrm{a}}$ série & Saraiva, São Paulo & 2005 \\
\hline $\begin{array}{l}\text { José Amabis e } \\
\text { Gilberto Martho }\end{array}$ & $\begin{array}{l}\text { Biologia, volume 2: biologia } \\
\text { dos organismos }\end{array}$ & $2^{\mathrm{a}}$ série & Moderna, São Paulo & 2004 \\
\hline Wilson Paulino & $\begin{array}{l}\text { Biologia, volume } 2 \text { : seres } \\
\text { vivos/ fisiologia }\end{array}$ & $2^{\mathrm{a}}$ série & Ática,São Paulo & 2005 \\
\hline $\begin{array}{l}\text { Sônia Lopes e } \\
\text { Sergio Rosso }\end{array}$ & Biologia: volume único & Ensino Médio & Saraiva,São Paulo & 2005 \\
\hline Oswaldo Frota-Pessoa & Biologia, volume 2 & $2^{\mathrm{a}}$ série & Scipione,São Paulo & 2005 \\
\hline $\begin{array}{l}\text { Augusto Adolfo; Marcos } \\
\text { Crozetta e Samuel Lago }\end{array}$ & Biologia: volume único & Ensino Médio & IBEP,São Paulo & 2005 \\
\hline
\end{tabular}

Fonte: Biologia: Catálogo do Programa Nacional do Livro para o Ensino Médio: PNLEM 2009 (Brasil, 2008).

\section{Resultados e discussão}

\section{A) Livros didáticos de ciências}

Seis livros de ciências, dentre os sete analisados, introduziram o tema leishmanioses dentro do assunto "Taxonomia", "Classificação dos Seres Vivos". A enfermidade foi contextualizada como exemplo de doença causada por protozoários no Reino Protista. Apenas o livro de Bortolozzo e Maluhy (2005) abordou a temática em "Relações Ecológicas", "Parasitismo", associando várias doenças parasitárias causadas por diferentes classes de agentes etiológicos. A abordagem do conteúdo dentro de taxonomia, geralmente, é a forma adotada por professores do Ensino Básico para lecionarem os conteúdos e seguirem os programas curriculares das escolas, o que pode restringir o tema aos aspectos biológicos e não estimular as relações saúde e sociedade, saúde e ambiente.

Dois livros referiram-se a leishmaniose (no singular) como se fosse um único tipo de doença e não especificaram suas duas formas clínicas: LTA e LV - Andrade et al. (2006) e Braga et al. (2006). Esse último livro apenas citou "Leishmaniose" e apresentou uma ilustração do seu vetor e agente etiológico de maneira solta, sendo as informações insuficientes para se compreender as doenças (Figura 1). Outros três livros referiram-se apenas a "Úlcera de Bauru" (denominação popular da LTA em algumas regiões brasileiras) como a única forma das leishmanioses: Barros e Paulino (2006), Godwdak e Martins (2006) e Costa (2006). O livro de Costa (2006) deu, como denominação similar a "Úlcera de Bauru", "Leishmaniose de pele". Nenhum desses três livros citou corretamente o nome da enfermidade, Leishmaniose 
França, V. H.; Margonari, C.; Schall, V. T.

Tegumentar Americana; ao contrário, reforçaram apenas o conhecimento dos nomes populares da LTA e favoreceram a permanência de desconhecimento da LV entre professores e alunos.

A denominação "Úlcera de Bauru" é uma nomenclatura estigmatizante da LTA, originada no início do século XX, quando operários da ferrovia noroeste, explorados sob péssimas condições de trabalho, eram afetados pela enfermidade na região da vila de Bauru, e excluídos na sociedade (BENCHIMOL; SILVA, 2008). Assim, tal denominação vem carregada de preconceito, o que deveria ser questionado nos textos, mas é dado como sinônimo da doença. Apenas dois livros descreveram a existência de mais de um tipo de Leishmaniose: Bortolozzo e Maluhy (2005), que referiram corretamente às denominações LTA e LV, e Gewandsnajder (2006), que citou somente a LTA.

Em relação ao agente etiológico das leishmanioses, seis livros didáticos citaram o protozoário Leishmania: Andrade et al. (2006), Barros e Paulino (2006), Gowdak e Martins (2006), Costa (2006), Gewandsnajder (2006), Bortolozzo e Maluhy (2005). Três desses denominaram a doença de "Úlcera de Bauru" e especificaram-na como causada por uma única espécie do parasita: a "Leishmania brasiliensis" - escrita com erro de ortografia (BARROS; PAULINO, 2006; GOWDAK; MARTINS, 2006; COSTA, 2006). A LTA tem, como agentes etiológicos mais comuns no Brasil, além da L. braziliensis, a L. amazonensis e a L. guyanensis essas duas últimas não foram descritas pelos livros didáticos. Apenas Bortolozzo e Maluhy (2005) descreveram a LV, mas não citaram seu agente etiológico, a L. chagasi (= L.infantum).

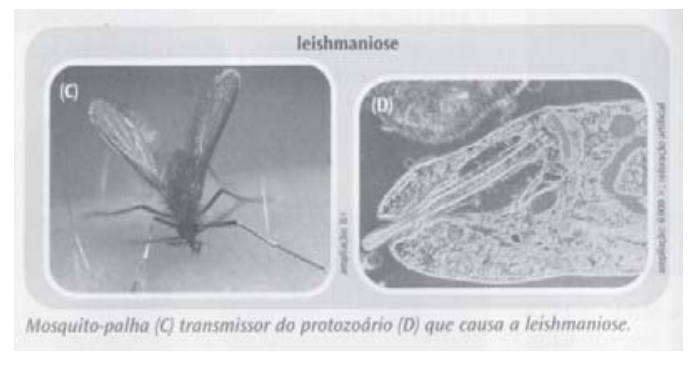

Figura 1. llustração de vetor e protozoário (partido) das leishmanioses, sem fonte e nomes científicos.

Fonte: Braga et al., 2006.

Por se tratarem de livros de ciências para o Ensino Fundamental e não ser necessário citar todas as espécies causadoras da enfermidade detalhadamente, a descrição da Leishmania, embora correta, pode induzir professores e alunos a pensarem equivocadamente que há uma única espécie dentro do gênero Leishmania causadora das leishmanioses. É importante que os livros de ciências descrevam o protozoário como Leishmania spp., pois cria-se a possibilidade de o aluno estabelecer contato com a nomenclatura científica, compreendendo que há várias espécies do parasita causadoras das doenças.

Barros e Paulino (2006) apresentaram um desenho do protozoário sem citar a fonte da imagem e sua escala de ampliação. Anexaram, ao mesmo, apenas a nomenclatura científica "Leishmania brasiliensis", com erro de ortografia. Braga et al. (2006), apesar de terem anexado 
uma eletromicrografia do protozoário, não especificaram sua nomenclatura científica, a fonte da imagem, nem disponibilizaram um texto explicativo. A figura continha apenas parte do parasita, com detalhes de sua morfologia, sendo, portanto, uma abordagem superficial e fragmentada do conteúdo e do agente etiológico, a qual não possibilita o reconhecimento e identificação de sua morfologia pelos leitores (Figura 1). Um único livro, Andrade et al. (2006), descreveu corretamente o protozoário e o ilustrou adequadamente por meio de uma microscopia de varredura contendo informações sobre o tamanho de sua ampliação e a fonte da imagem.

Todos os livros de ciências analisados citaram o vetor das leishmanioses como "mosquito", "mosquito-palha", e alguns "biriguil" (denominações populares, Figuras 1 e 2). Tais informações associam a transmissão da enfermidade aos mosquitos, e não aos flebotomíneos. Os mosquitos pertencem à família Culicidae e precisam da água para se reproduzirem, enquanto os flebotomíneos pertencem à família Psychodidae e se reproduzem em matéria orgânica em decomposição. Essa informação é de extrema importância, pois explica as diferenças nas ações preventivas entre doenças causadas por mosquitos, por exemplo, o Aedes aegypti (Dengue), e as causadas por flebotomíneos (Lutzomyia) - leishmanioses.

Dois livros didáticos, além de citarem o mosquito como vetor, acrescentaram a essa descrição o gênero Lutzomyia (Figura 2): Bortolozzo e Maluhy (2005), Andrade et al. (2006). Ressalta-se que o gênero Lutzomyia é específico de insetos flebotomíneos. No livro de Andrade et al. (2006, p. 13), esse gênero ainda foi escrito com erro de ortografia: "Lutromia".

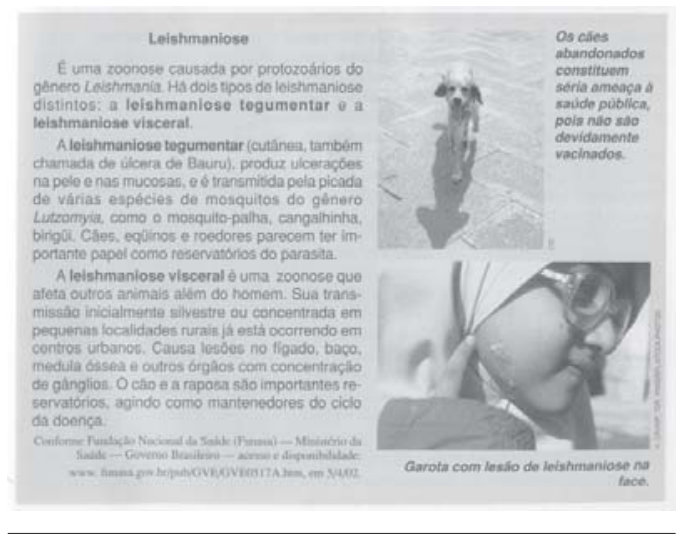

Figura 2. Texto apresentando conceitos errados, descrição indevida de vacinação e lesão não característica da LTA.

Fonte: Bortolozzo e Maluhy (2006).

Barros e Paulino (2006, p. 87) também se referiram ao flebotomíneo de forma errônea: "transmitida ao ser humano por meio da picada do mosquito flebótomo (gênero Phlebotomus) popularmente conhecido como mosquito-palha ou birigui, entre outras denominações [...]". Esse livro, embora seja o único a citar os flebotomíneos e seu gênero, e associar o nome científico ao popular, valorizando a linguagem cotidiana, comete duas falhas: a primeira, se 
França, V. H.; Margonari, C.; Schall, V. T.

referir ao flebotomíneo como mosquito; e a segunda, classificar os mesmos dentro do gênero Phlebotomus, inexistente no Brasil e presente somente em países do Velho Mundo.

Cinco livros omitiram os reservatórios das leishmanioses, apontando uma incoerência e lacuna grave na abordagem do conteúdo - Barros e Paulino (2006); Costa (2006); Braga et al. (2006); Gowdak e Martins (2006); Gewandsnajder (2006). Apenas dois livros associaram a doença ao cão como reservatório. Andrade et al. (2006, p. 13) descreveram que "os cães estão na origem de muitos casos humanos [...] o mosquito-palha pica um cão doente e depois uma pessoa, levando o protozoário do cão para a pessoa". Outro livro, de Bortolozzo e Maluhy (2005, p. 141), citou o cão e outros animais como prováveis reservatórios da LTA: "Cães, eqüinos e roedores parecem ter importante papel como reservatórios do parasita"; os autores fizeram um breve comentário sobre a LV afirmando: "O cão e a raposa são importantes reservatórios, agindo como mantenedores do ciclo da doença" (BORTOLOZZO; MALUHY, 2005, p. 141) (Figura 2).

É comprovado que o principal reservatório urbano para a LV é o cão. Embora alguns estudos, como Massunari et al. (2009) e Figueiredo et al. (2009), descrevam esse animal como um reservatório urbano em áreas endêmicas, tanto para LV quanto para a LTA, devido à presença de infecções associadas com a L.chagasi e L. bražiliensis; é importante ressaltar que há controvérsias com relação a essa questão.

Segundo Reithinger, Espinoza, Davies (2003), em Huánuco, Peru, área endêmica para a LTA, os cães infectados apresentam baixa carga parasitária nas lesões e altas taxas de cura parasitológica para a doença. Dantas-Torres (2007), em revisão de literatura sobre a temática e fundamentando-se em vários estudos, comentam que os cães têm baixa competência como reservatórios da LTA. Para esses últimos pesquisadores, são necessárias pesquisas sobre o envolvimento dos cães no ciclo de transmissão da LTA, pois esses ainda não são comprovados como reservatórios da L. braziliensis.

Pouco se encontra, nos livros de ciências, sobre as manifestações e sintomas das leishmanioses. Quatro livros, citando a "Úlcera de Bauru" e a "Leishmaniose Tegumentar", descreveram o comprometimento cutâneo e mucocutâneo como concomitantes: Barros e Paulino (2006); Gowdak e Martins (2006); Bortolozzo e Maluhy (2005); Gewandsnajder (2006). Nenhum livro especificou os subtipos da LTA (cutânea, mucocutânea e difusa) e suas respectivas manifestações clínicas separadamente. Embora esse seja um conhecimento científico muito especializado para escolares mirins, poderia ser referido e indicadas fontes de consulta para aqueles que quiserem saber mais. O que fica claro é que, da forma abordada, torna-se uma informação superficial e pouco útil para a vida dos aprendizes.

A LTA mucocutânea pode gerar ulcerações mucosas na cavidade oral e vias aéreas superiores; a LTA cutânea produz lesões ulceradas no tegumento, e a LTA difusa, lesões nodulares (BRASIL, 2009c). O fato de esses livros citarem as manifestações da LTA cutânea associadas às da LTA mucocutânea, pode induzir os leitores a pensarem que a "Úlcera de Bauru" compreende um único tipo de doença e que esse resulta na coexistência de todos os sintomas descritos. As estatísticas apontam que 3\% a 5\% dos casos de LTA cutânea evoluem para a forma mucocutânea (LUZ et al., 2003; BRASIL, 2009c). Aqui seria mais pedagógico especificar, nos livros de ciências, que a forma mais comum da LTA é a cutânea, e que essa resulta em lesões ulceradas na pele; porém que existem outras formas da doença, e, dentre essas, a mais comprometedora destrói as mucosas e gera desfigurações nos portadores. Essa, 
sim, seria uma informação que poderia levar os estudantes a fazerem conexão com casos de sua realidade, sobretudo aqueles que vivem em áreas endêmicas, bem como estimular o conhecimento sobre prevenção e tratamento.

O livro de Barros e Paulino (2006, p. 86) descreveu equivocadamente que a LTA, além de causar lesões na pele e mucosas, contribui para que portadores apresentem "sono agitado e insônia". Esses dois últimos sintomas citados são indevidos, pois não foram encontrados em publicações científicas e livros abordando a temática. O livro de Bortollozo e Maluhy (2005), embora cite corretamente a denominação da LTA, comete duas falhas: associa os sintomas da forma cutânea com a mucocutânea, e apresenta foto de lesões da LTA cutânea imprópria, pois essas não são típicas da doença e podem promover a confusão com outras enfermidades e prejudicar sua suspeita e identificação (Figura 2). Ressalta-se aqui o pouco cuidado com que as ilustrações são, muitas vezes, incluídas na publicação, quando poderiam ser fonte relevante de identificação de sintomas, potencializando a aprendizagem.

Esse mesmo livro descreveu a LV e suas manifestações: "causa lesões no fígado, baço, medula óssea e outros órgãos com concentração de gânglios" (BORTOLOZZO; MALUHY, 2005, p. 141) (Figura 2). A descrição "concentração de gânglios" é inadequada, tal comprometimento pode ser descrito corretamente como infecção do protozoário nos gânglios linfáticos. Embora não seja uma prioridade dos livros de ciências do Ensino Fundamental descreverem em detalhes todos os sintomas e sinais das doenças, é fundamental que a LV seja citada e destacada como a forma mais grave das leishmanioses, pois, se não for tratada, pode evoluir para óbito. Apesar disso, apenas um livro a descreveu.

Nenhum livro de ciências apresentou medidas de controle e prevenção adequadas. $\mathrm{O}$ livro de Bortolozzo e Maluhy (2005), contraditoriamente, mostra a ilustração de um cão emagrecido, chamando a atenção sobre a importância da vacinação animal para se prevenirem as leishmanioses (Figura 2). Os Ministérios da Saúde e da Agricultura, Pecuária e Abastecimento (MAPA) publicaram uma Nota de Esclarecimento sobre as Vacinas Anti-leishmaniose Visceral Canina registradas no MAPA, divulgando a não-recomendação do seu uso na saúde pública. A vacinação de cães para a LV não é recomendada pelo MS porque as pesquisas referentes às vacinas Leishmune e LeishTec encontram-se ainda na fase III dos testes; não sendo, portanto, totalmente comprovadas sua eficácia, segurança, inocuidade, proteção à infecção, imunogenicidade. Segundo o MS, estão sendo realizados estudos para avaliar seu uso para esse fim (BRASIL, 2009a).

É importante refletir que o modelo de prevenção divulgado nos livros didáticos (e, de modo geral, nos materiais educativos e informativos sobre saúde) ainda veicula o discurso biomédico de modo impositivo. Esse discurso limita-se a transmitir conteúdos técnicos considerados relevantes em relação às enfermidades, sem considerar o contexto local das comunidades e valorizar-lhes os conhecimentos e participação nesse processo. Referir apenas as medidas de caráter biomédico, nem sempre ao alcance da população, não a faz participar das ações profiláticas. Poderiam ser discutidas, nos livros, ações preventivas de educação em saúde acessíveis à população, assim como estimulado o exercício do direito à informação e prevenção, além da luta por políticas públicas em saúde. Percebe-se que os temas de saúde, ao serem inseridos nos livros de ciências, são tratados com menor rigor científico, de forma superficial, em menor espaço, e pouco auxiliam no processo de ensino-aprendizagem. Tais temas deveriam se destinar não apenas à aquisição de novos conhecimentos, mas à promoção da saúde dos estudantes. 
França, V. H.; Margonari, C.; Schall, V. T.

Ressalta-se que cinco livros de ciências apresentaram ilustrações com boa qualidade gráfica, embora o número dessas, em alguns livros, ainda seja insuficiente para esclarecer algumas características das doenças junto aos alunos. As ilustrações mais comuns foram do "mosquito-palha" e da "Leishmania". Apenas um livro anexou foto do cão e da lesão causada pela LTA, sendo que as mesmas foram consideradas inadequadas ao que se propõem (Figura 2). Três livros acrescentaram, ao lado das ilustrações, a fonte da imagem: Andrade et al. (2006), Costa (2006), Bortolozzo e Maluhy (2005). Quanto a informações de escala de tamanho ou de ampliação das fotos do protozoário e do vetor, somente três livros anexaram tais detalhes: Andrade et al. (2006), Costa (2006), Braga et al. (2005).

Nenhum livro de ciências ilustrou o ciclo de transmissão das leishmanioses e apresentou dados epidemiológicos sobre a situação das doenças no Brasil. Tais informações poderiam elucidar os alunos sobre sua ocorrência na realidade, mesmo que tais desenhos e dados fossem simplificados para se adequarem ao Ensino Fundamental.

A forma como o conteúdo das leishmanioses é disponibilizado nos livros de ciências gera distorções no ensino e aprendizagem do conteúdo. A linguagem dos livros segue relativamente o mesmo padrão didático: na tentativa de adequá-la à faixa etária dos escolares de $5^{a}$ e $6^{\text {a }}$ série do Ensino Fundamental, os textos apresentam um discurso banalizado, apelam para noções do senso comum que descaracterizam as especificidades das doenças. São empregados, em tais materiais, termos que apelam, sobretudo, para as denominações populares da LTA e do vetor, o que tem valor se associado ao saber científico correlato, pois a escola é o local onde a ciência deve ser aprendida. Essas inadequações associadas às medidas preventivas normativas minimizam a magnitude de tal problema para a saúde pública e a importância de a população participar no processo profilático. Os livros de ciências desconsideraram, também, o contexto geográfico e socioeconômico dos escolares, e não estabeleceram: a relação do ciclo biológico, manifestações clínicas e medidas preventivas com o ambiente cotidiano, seja esse urbano ou rural. Os conceitos divulgados na maioria desses materiais não suscitam a reflexão sobre as doenças e não fomentam o compromisso social dos leitores com ações coerentes ao seu enfrentamento.

\section{B) Livros de Biologia}

Seis livros didáticos de biologia, dentre os nove selecionados, introduziram o conteúdo das leishmanioses da mesma forma que a maioria dos livros de ciências, a partir de "Taxonomia", "Reino Protista". Apenas três livros de biologia abordaram o tema de modo diferente, ao descreverem sobre "Parasitismo" e "Endemias", de modo geral, associando várias doenças em um mesmo capítulo: Favaretto e Mercadante (2005), Frota-Pessoa (2005), Silva Júnior e Sazzon (2005). Verificou-se, na análise, que os livros de biologia seguem o mesmo padrão didático, na abordagem dos conteúdos, que a maioria dos livros de ciências, todos com ênfase biomédica e distantes da reflexão sobre saúde e sociedade.

Seis livros de biologia abordaram os dois tipos clínicos das leishmanioses: LTA e LV, sendo exceção os livros de Adolfo, Crozetta e Lago (2005); Laurence (2005); Frota-Pessoa (2005). Os livros de Adolfo, Crozetta e Lago (2005) e Laurence (2005, p. 265) descreveram apenas um tipo das doenças, a "Úlcera de Bauru". O último referiu-se a essa, também, de forma incompleta, como "Leishmaniose cutânea". Frota-Pessoa (2005) citou, em dois capítulos 
separados - "Parasitismo" e "Endemias", respectivamente -, "Leishmaniose", ao abordar o ciclo de transmissão, e LTA, dentro de quadro sobre endemias do Brasil. Esses três livros pontuaram o tema de modo superficial e fragmentado, contribuindo para o desconhecimento de professores e alunos em relação às leishmanioses. Lopes e Rosso (2005, p. 218) citaram a LV, mas denominaram errado a LTA como "Úlcera de Bauru ou Leishmaniose de Pele". Favaretto e Mercadante (2005, p. 229) citaram corretamente a LV, porém, de forma incompleta, a LTA como "Leishmnaniose cutânea-mucosa ou Úlcera de Bauru". Conforme comentado, a denominação "Úlcera de Bauru" é uma forma estigmatizante de se referir à LTA. Se apresentada em contexto histórico e questionador, poderia tornar-se um tema propício para associar saúde e cidadania e superação de estigmas, tornando o processo de aprendizagem mais rico para a formação científica e sociocultural dos estudantes.

Todos os livros de biologia citaram o protozoário Leishmania. Frota-Pessoa (2005), no capítulo sobre "Parasitismo", citou "Leishmania" e "Leishmânias" (essa com erro de ortografia), ao abordar o ciclo de transmissão da doença (Figura 3); no capítulo "Endemias", citou novamente "Leishmania" ao referir-se ao agente da LTA. Laurence (2005, p. 265), ao referir-se às "leishmanioses", descreveu que as doenças são "causadas por protozoários flagelados do gênero Leishmania", sendo que o agente etiológico também apresenta, na metaciclogênese, uma fase sem flagelo, denominada amastigota. Os outros sete livros descreveram as espécies de Leishmania de acordo com os tipos clínicos - LTA e LV. Nesses livros, foi especificada como espécie de agente etiológico da LTA apenas a L. braziliensis, não sendo citadas a $L$. amaz̧onensis e a L. guyanensis - espécies comuns em várias regiões do Brasil. Quatro, dentre esses sete livros, citaram a "L. brasiliensis" com erro de ortografia no nome científico: Silva Junior e Sazzon (2005), Lopes e Rosso (2005), Amabis e Martho (2004), Paulino (2005). Em se tratando de Ensino Médio, ressalta-se aqui a necessidade de se poder focalizar com mais detalhes o conhecimento científico e sua nomenclatura, mas, percebe-se que tal não acontece.

O livro de biologia de Paulino (2005), assim como o livro de ciências de Barros e Paulino (2006), anexou, ao texto sobre leishmanioses, uma ilustração do protozoário, denominando-o como "L. brasiliensis" (com s) e com vários outros erros: não há, no desenho, a estrutura do cinetoplasto, importante organela desse protozoário, nem a fonte e escala da imagem (Figura 4). Esse último livro e o de Amabis e Martho (2004) citaram, ainda, a Leishmania tropica como agente etiológico das leishmanioses, sendo que essa espécie não ocorre no Brasil, apenas em países do Velho Mundo. Paulino (2005) descreveu que essa causa a doença "Botão do Oriente" - denominação popular da LTA; e Amabis e Martho (2004) cometeram sério erro ao associá-la ao acometimento de órgãos internos, ou seja, à LV.

Apenas seis livros citaram a espécie de Leishmania como causadora da LV. Dentre esses, três o fizeram corretamente, escrevendo Leishmania chagasi: Lopes e Rosso (2005); Linhares e Gewandsznajder (2005); Amabis e Martho (2004). Os outros três livros citaram a Leishmania donovani, que não ocorre no Brasil, como agente etiológico da LV: Favaretto e Mercadante (2005); Silva Júnior e Sazzon (2005); Paulino (2005). É importante que alunos do Ensino Médio passem por processos de aprendizagem com informações corretas, e não superficiais, sobre: os agentes etiológicos, as diferentes espécies de vetores das doenças, sua nomenclatura científica e regiões endêmicas e epidêmicas, contextualizados ao Brasil. Os equívocos põem a perder a aprendizagem sobre a doença, pois focam em nomes e imagens inadequados, tornando o conteúdo de saúde de baixa qualidade e sem pontes com a realidade do país. 


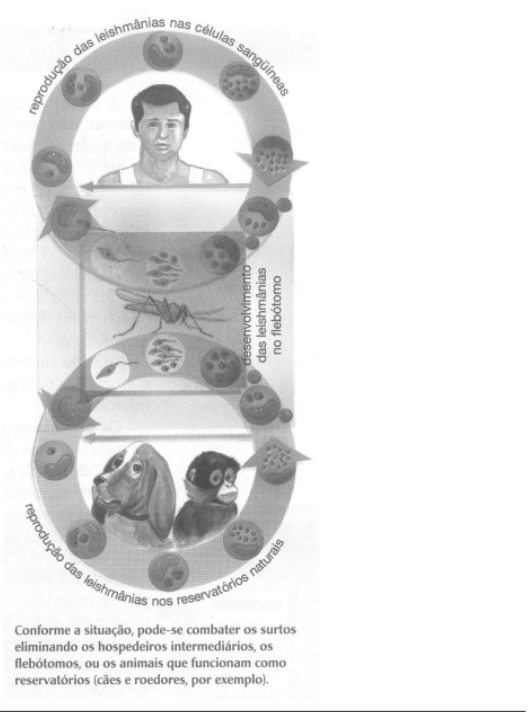

Figura 3. Ciclo de transmissão com vetor, reservatórios e prevenção inadequados.

Fonte: Frota-Pessoa (2005).

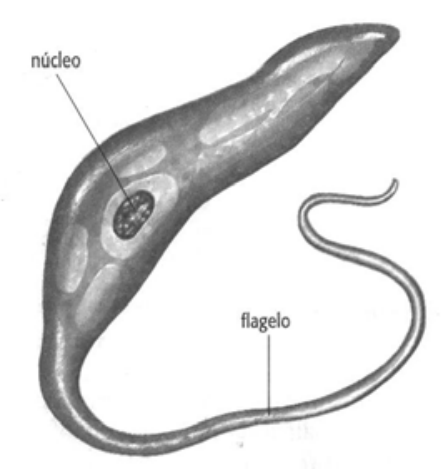

Fig. 4.11 - Leishmania brasiliensis, protozoário transmitido aos seres humanos pela picada de mosquito conhecido popularmente como mosquito-palha ou birigui.

Todos os livros de biologia, assim como todos os livros de ciências, descreveram, de forma imprópria, o vetor como "mosquito". Seis referiram-se ao vetor acrescentando seu nome popular "mosquito-palha": Amabis e Martho (2004); Linhares e Gewandsznajder (2005); Favaretto e Mercadante (2005); Laurence (2005); Silva Júnior e Sazzon (2005); Lopes e Rosso (2005). Seis livros também associaram equivocadamente o "mosquito" ao gênero "Lutzomyia", como se ambos fossem da mesma família de insetos: Amabis e Martho (2004); Linhares e Gewandsznajder (2005); Favaretto e Mercadante (2005); Laurence (2005); Silva Júnior e Sasson (2005); Adolfo, Crozetta e Lago (2005). O livro de Amabis e Martho (2004) citou a "Lutzomya longipalpis" com dois erros: um de ortografia científica e outro por associar essa espécie como vetora da LTA, sendo que a $L$. longipalpis é vetora da LV.

Paulino (2005) e Frota-Pessoa (2005) associaram o vetor ao "mosquito" e classificaramno dentro do gênero "Phlebotomus", inexistente no Brasil. Lopes e Rosso (2005), Laurence (2005), Favaretto e Mercadante (2005), Linhares e Gewandsznajder (2005), citaram as palavras "flebótomo", "flebotomíneos", associando-as ao nome popular "mosquito-palha". Tal associação pode favorecer a confusão das leishmanioses com doenças cujos vetores são mosquitos, tais como a Dengue. Frota-Pessoa (2005) citou o "flebótomo" no ciclo biológico da doença e o representou com características que não condizem morfologicamente com insetos do gênero Lutzomyia; sendo que o desenho não apresenta escala e dificulta a identificação do vetor (Figura 3).

Em relação aos reservatórios, sete livros de biologia não os citaram: Paulino (2005), Amabis e Martho (2004), Linhares e Gewandsznajder (2005), Laurence (2005), Silva Júnior e Sasson (2005), Adolfo, Crozetta e Lago (2005), Lopes e Rosso (2005). O livro de Frota-Pessoa 
(2005) anexou uma ilustração do ciclo de transmissão com desenhos do cão e primata, sendo que este último não é reservatório comprovado das leishmanioses no Brasil (Figura 3). O livro de Favaretto e Mercadante (2005) foi o único a apresentar os reservatórios da LTA e LV de forma coerente.

Há uma grave lacuna de informação sobre os reservatórios das leishmanioses nos livros didáticos de biologia. É importante destacar que, para haver a prevenção e o controle das doenças, é fundamental conhecê-los. Tanto os livros de biologia quanto os de ciências deveriam citar a informação de que os cães são os principais reservatórios da LV nas áreas urbanas, pois, de acordo com a Secretaria de Vigilância em Saúde (SVS, 2009), no Brasil, a epidemia humana pela doença está associada à ocorrência de cães soropositivos.

Com relação às manifestações clínicas das leishmanioses, Adolfo, Crozetta e Lago (2005) não as citaram. Frota-Pessoa (2005) e Laurence (2005) descreveram, respectivamente, que a LTA e a "Úlcera de Bauru" causam ulcerações na pele. Tais informações são insuficientes para promoverem a compreensão da sintomatologia pelos alunos do Ensino Médio.

Seis livros de biologia apresentaram, em seu texto, as principais manifestações da LTA e da LV separadamente, demonstrando uma ênfase mais aprofundada nos conteúdos quando comparados com os livros de ciências: Amabis e Martho (2004), Lopes e Rosso (2005), Silva Júnior e Sasson (2005), Linhares e Gewandsznajder (2005), Paulino (2005), Favaretto e Mercadante (2005). Os quatro últimos livros associaram as manifestações da LTA cutânea e mucocutânea como se fossem uma única forma clínica da enfermidade. É imprescindível que estudantes e professores do Ensino Médio sejam esclarecidos sobre as diferentes formas da LTA e seus sintomas detalhados. A explicação sobre as diferentes formas de essa se manifestar pode promover a conscientização de professores e alunos da importância de se prevenir a doença. Essa pode culminar em complexos comprometimentos físicos e psicológicos, sendo que sua terapêutica varia de acordo com suas formas clínicas. Seria apropriado, portanto, os livros de biologia enfatizarem as conseqüências clínicas da LTA e citarem, em especial, a gravidade de sua forma mucocutânea, devido ao seu desfecho, dependendo das variáveis agente etiológico, condições físicas e nutricionais do paciente. Além disso, ressaltar que o tratamento precoce previne a evolução das lesões. Isso não foi verificado em nenhum livro.

O livro de biologia de Paulino (2005, p. 60) repete o mesmo erro do livro de ciências de Barros e Paulino (2006): cita que a LTA pode "causar a obstrução parcial das cavidades nasais e vias aéreas superiores, determinando sonos agitados e insônia, que afetam a produtividade do doente no trabalho". As leishmanioses são doenças que levam os portadores a se apresentarem incapazes para o trabalho e atividades de vida diária; contudo, a referência ao sono agitado e insônia não é encontrada na literatura científica. Schall e Diniz (2001) observaram que alguns materiais educativos são elaborados como cópias uns dos outros e reproduzem, também, os erros, o que se repete na presente análise.

No livro de Favaretto e Mercadante (2005, p. 229), ao abordarem a LTA mucocutânea, foi observada uma informação com vocabulário impróprio: "A destruição da cartilagem nasal leva ao desabamento do nariz ('nariz de anta')". Embora a doença cause o comprometimento das cartilagens do palato e nasal, podendo gerar lesões desfigurantes, não é mais empregada a denominação "nariz de anta" ou "nariz de tapir". Esses termos reproduzem estigmas e preconceitos em relação aos portadores da LTA mucocutânea, favorecendo sua exclusão social e distanciamento dos serviços de saúde. Aqui, novamente, perde-se a oportunidade de um 
França, V. H.; Margonari, C.; Schall, V. T.

enfoque histórico e questionador de estigmas que pode tornar o ensino comprometido com a formação para a cidadania, em lugar de ser meramente descritivo e memorizador.

Apenas um livro descreveu a LTA cutânea e a diferenciou corretamente da LTA mucocutânea, destacando que, na pele, as lesões apresentam "bordas elevadas e fundo granuloso [...] nas lesões mucosas (cavidade nasal, faringe ou laringe), a Leishmaniose destrói tecidos, e em casos graves pode perfurar o septo nasal e causar lesões deformantes" (AMABIS; MARTHO, 2004, p. 105). Esse livro foi o único a anexar ilustração apropriada e contextualizada de lesão da LTA, mas não especificou qual a forma clínica representada.

Com relação à sintomatologia da LV em seres humanos, apenas seis livros abordaram a questão: Amabis e Martho (2004), Lopes e Rosso (2005), Linhares e Gewandsznajder (2005), Silva Júnior e Sasson (2005), Paulino (2005), Favaretto e Mercadante (2005). Essa descrição é caracterizada pela presença de febre, aumento do baço e fígado, enfraquecimento. Apenas três livros destacaram que a LV pode levar ao óbito: Amabis e Martho (2004), Linhares e Gewandsznajder (2005), Favaretto e Mercadante (2005). Dois livros de biologia, Paulino (2005) e Favaretto e Mercadante (2005), explicaram as manifestações da LV de forma mais detalhada e adequada para professores e estudantes do Ensino Médio. Esses acrescentaram, aos sinais e sintomas citados, outros relevantes e característicos da doença, tais como: comprometimento da medula óssea, perda de apetite, anemia, leucopenia.

Em Lopes e Rosso (2005, p. 217), foi observada uma descrição indevida com relação aos sintomas da LV: lesões nos "intestinos". Segundo o MS, a LV pode gerar o "acometimento gastrointestinal" e a "hemorragia digestiva", mas essas manifestações ocorrem com complicações no curso evolutivo da doença ou quando essa ocorre com coinfecção Leishmania/HIV (BRASIL, 2009c, p.31 e 34). O livro de Amabis e Martho (2004, p.105), ao descrever sobre a LV, acrescentou, aos sintomas corretos, outros errados: "lesões de pele" e "febre contínua". As "lesões de pele" são característica da LTA, e a ocorrência de "febre contínua" deve ser corrigida para febre recorrente com remissões, nos casos mais comuns, quando o portador é acometido pela forma clássica da LV. Apenas nesse livro foi descrito o tratamento da LV com medicamento à base de Antimônio, dando destaque a sua alta toxicidade; entretanto, não foi explicado que a terapêutica da LTA é com o mesmo medicamento e ocorre com dosagem diferente. Frota-Pessoa (2005, p.125) citou inadequadamente, como tratamento da LTA, a "cura espontânea, remédios que contenham Antimônio". O MS ressalta que as lesões da LTA cutânea, "caso não tratadas, tendem à cura espontânea em período de alguns meses a poucos anos", mas podem "permanecer ativas por vários anos e coexistir com lesões mucosas de surgimento posterior" (BRASIL, 2009c, p.3); sendo necessária a terapêutica com Antinômio para ocorrer sua cura.

Um tópico fundamental, que não foi adequadamente descrito nos livros de biologia, são as medidas preventivas e de controle das leishmanioses. $\mathrm{O}$ assunto foi abordado apenas em cinco livros: esses referiram-se ao combate do vetor - Lopes e Rosso (2005) - e, sobretudo, ao "combate do mosquito" - Frota- Pessoa (2005, p. 125); Amabis e Martho (2004), Linhares e Gewandsznajder (2005), Favaretto e Mercadante (2005). Os três últimos livros acrescentaram também o uso de telas em portas e janelas para prevenção, sem ressaltar que essas devem ser de malha fina, pois os flebotomíneos têm de 1 a $3 \mathrm{~mm}$ de comprimento. Amabis e Martho (2004, p. 105) especificaram, de maneira indevida, "cobrir camas com cortinado de filó"; embora esse seja um método preventivo individual, a trama larga do tecido não é eficiente contra os vetores das leishmanioses. 
Linhares e Gewandsznajder (2005) citaram imprecisamente que, para prevenir o "mosquito" da LTA, as casas devem ser construídas com, no mínimo, uma distância de 100 metros das matas. Porém, o MS recomenda que, em "áreas rurais com alto potencial de transmissão", essa distância seja entre 400 a 500m (BRASIL, 2009b, p. 79). Esses autores também veicularam outra informação imprópria, descreveram a profilaxia da LTA citando a existência de vacina. Essa medida não é recomendada pelo MS por motivos expostos anteriormente.

Outra falha em relação à prevenção das leishmanioses, que também deve ser apontada como grave, foi descrita por Amabis e Martho (2004, p. 105): “o combate ao mosquito pode ser feito pelo aterro de lagoas e poças d'água que servem de criadouro para as larvas”. Os locais propícios como criadouros para flebotomíneos são áreas com acúmulo de matéria orgânica em decomposição (folhas secas, lixo orgânico e fezes de animais), e não a água, que é criadouro para "mosquitos". O aterro de lagoas não previne as leishmanioses; é uma ação imprópria para a sustentabilidade do meio ambiente e manutenção de sua biodiversidade.

Frota-Pessoa (2005, p. 121) também cometeu falha quanto às medidas preventivas: apresentou ilustração do ciclo de transmissão das leishmanioses sugerindo "combater os surtos eliminando os hospedeiros intermediários, os flebótomos, ou animais que funcionam como reservatórios (cães e roedores, por exemplo)" (Figura 3). Tais medidas encontram-se escritas com vocabulário impróprio, deveriam ser referidas como eutanásia de cães soropositivos para LV e controle de vetores. Os termos hospedeiros intermediários e definitivos não são usuais no meio científico, e a eliminação de todos os flebotomíneos, além de não ser viável, exigiria uma pulverização de inseticidas de alta toxicidade, em grande escala, que poderia gerar graves prejuízos para a saúde humana, outras espécies de animais e ao meio ambiente. Devido a essa toxicidade, os inseticidas são empregados apenas em áreas comprovadamente de risco, por profissionais de saúde das zoonoses capacitados, e com cuidados específicos: não é realizada a aplicação do inseticida em regiões de mata, somente se pulverizam as superfícies de paredes do domicílio e anexos, incluindo abrigos de animais domésticos e paióis (BRASIL, 2009c).

As medidas preventivas e de controle para as leishmanioses citadas nos livros de biologia apresentam erros e linguagem técnica sanitarista imprópria. São descritas informações de educação em saúde normativas e descontextualizadas à realidade, que não promovem a participação da comunidade no processo profilático. É importante que essas medidas alcancem a comunidade em sua totalidade. Poderiam ser descritas como medidas preventivas acessíveis à população: limpeza das áreas peridomiciliares, incluindo a retirada de matéria orgânica em decomposição; armazenamento e destino adequado do lixo orgânico, para se evitarem criadouros de flebotomíneos e roedores; utilização de mosquiteiros de malha fina e telas nas portas e janelas; uso de camisas, calças compridas, meias e sapatos, e de repelentes em áreas de risco; higienização dos abrigos de animais domésticos, com retirada de matéria orgânica em decomposição; cuidado para não haver exposição aos ambientes de risco nos horários de crepúsculo matutino, vespertino e à noite (BRASIL, 2009c).

Apenas o livro de Amabis e Martho (2004) descreveu o número de casos de leishmanioses que ocorrem no Brasil, citando cerca de vinte mil pessoas acometidas ao ano. Os dados epidemiológicos da enfermidade são relevantes, embora desatualizados. Para a conscientização da população e promoção de sua ação no enfrentamento das doenças, é fundamental que tais materiais divulguem informações atuais sobre a situação da LTA e LV 
França, V. H.; Margonari, C.; Schall, V. T.

no país, e estabeleçam sua relação com o cotidiano da comunidade. Contudo, quatro livros de biologia descreveram o conteúdo na forma de quadros, citando apenas o nome da doença, o agente etiológico, sintomas e prevenção, como se tais informações soltas fornecessem a aprendizagem: Frota-Pessoa (2005), Lopes e Rosso (2005), Silva Júnior e Sasson (2005), Favaretto e Mercadante (2005).

A linguagem dos livros de biologia é menos banalizada que a dos livros de ciências, sendo mais adequada à faixa etária do Ensino Médio, pois os primeiros apresentam um número maior de informações que vão além do senso comum, apesar dos erros conceituais apontados; e estabelecem um pouco mais de relação do conteúdo com o ambiente, ao citarem as medidas preventivas. Entretanto, não apresentam informações contextualizadas à realidade geográfica e socioeconômica dos leitores, nem discutem as diferenças regionais e a relação com os hábitos culturais e aspectos políticos, como: acesso aos serviços públicos de saneamento, limpeza urbana etc. A forma como as medidas de prevenção são citadas nesses materiais passa, ainda, a impressão de que a LTA e LV acontecem limitadas ao ambiente rural.

No geral, os livros de biologia são um pouco melhores do que os de ciências, como demonstrado pelos percentuais da Tabela 1, o que está sumarizado nas conclusões a seguir.

\section{Conclusões}

Foram encontrados erros e lacunas de informação em todos os livros analisados (Tabela 1). Embora os livros de ciências apresentem um percentual menor de erros que os de biologia, há, nos primeiros, 64,3\% de informações incompletas, enquanto, nos livros de biologia, $53,3 \%$. Apenas há 10,0\% de conteúdo correto nos livros de ciências e 14,5\% nos de biologia. Quanto aos conteúdos errados, esses percentuais são mais próximos, 25,7\% nos livros de ciências, e 32,2\% nos de biologia.

Vários livros de ciências e biologia reproduziram os mesmos erros e lacunas de informação em relação a um determinado subtema, sendo os erros mais comuns: agentes etiológicos, vetores, sintomas clínicos humanos. As principais lacunas de informação foram: reservatórios e medidas de prevenção e controle, dados epidemiológicos, consequências clínicas e aspectos socioculturais envolvidos com a transmissão, e crescente prevalência da doença no Brasil. Pesquisas de Schall (2010) e Batista, Cunha e Cândido (2010) sobre análise de livros didáticos em relação a outros temas da área de saúde também verificaram a presença de conceitos científicos incorretos. É importante ressaltar que o estudo não se destinou apenas a apontar erros, mas a compreender como a saúde é focalizada nos livros de ciências; contudo, numa primeira análise, as evidências preponderantes de equívocos promoveram a necessidade de que fossem registrados e divulgados. A despeito das incorreções, o que permanece e é pedagogicamente inadequado é a forma tradicional de se apresentarem os conteúdos, com ênfase na memorização de aspectos biomédicos, sem relação com os fatores históricos, socioculturais e econômicos e com o contexto, vida cotidiana e saúde dos escolares.

Verificou-se que os livros analisados abordando as leishmanioses não estabeleceram a relação entre: saúde e ambiente, com o contexto local dos professores e alunos, e com a realidade brasileira. A linguagem adotada por tais materiais caracteriza-se por um discurso pautado em nomes, sintomas e procedimentos a serem decorados. 
Análise do conteúdo das leishmanioses ...

Tabela 1. Análise dos livros de ciências (PNLD 2008) e biologia (PNLEM 2009), em relação às leishmanioses.

\begin{tabular}{|c|c|c|c|c|c|c|c|c|c|c|c|c|c|}
\hline & \multirow{2}{*}{ 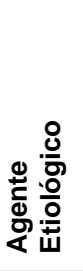 } & \multirow{2}{*}{ 衣 } & \multirow{2}{*}{ 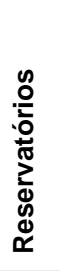 } & \multirow{2}{*}{ 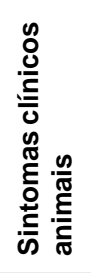 } & \multirow[b]{2}{*}{$\exists$} & \multirow{2}{*}{$\stackrel{\leftarrow}{\leftrightarrows}$} & \multirow{2}{*}{ 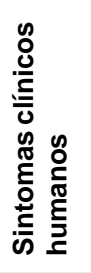 } & \multirow{2}{*}{ 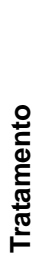 } & \multirow{2}{*}{ 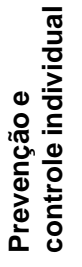 } & \multirow{2}{*}{ 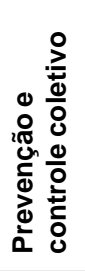 } & \multicolumn{3}{|c|}{ Total } \\
\hline & & & & & & & & & & & C & E & $\mathbf{I}$ \\
\hline \multicolumn{14}{|l|}{ Livros de Ciências } \\
\hline $\begin{array}{l}\text { Bortolozzo e Maluhy, } \\
2006\end{array}$ & C & $\mathrm{E}$ & C & I & $\mathrm{C}$ & C & $E$ & 1 & 1 & $E$ & 4 & 3 & 3 \\
\hline Barros e Paulino, 2006 & $E$ & $E$ & I & 1 & I & $E$ & $E$ & 1 & I & 1 & - & 4 & 6 \\
\hline Gewandsznaj-der, 2006 & $\mathrm{C}$ & $E$ & I & 1 & I & $\mathrm{C}$ & $E$ & I & 1 & $E$ & 2 & 3 & 5 \\
\hline Andrade et al, 2006. & $\mathrm{C}$ & $E$ & I & I & I & I & 1 & I & I & 1 & 1 & 1 & 8 \\
\hline Gowdak e Martins, 2006 & $E$ & $\mathrm{E}$ & I & I & I & $E$ & $E$ & 1 & 1 & E & - & 5 & 5 \\
\hline Costa, 2006 & $\mathrm{E}$ & 1 & 1 & 1 & 1 & E & 1 & I & 1 & I & - & 2 & 8 \\
\hline Braga et al., 2006 & I & I & I & I & I & I & 1 & I & 1 & 1 & - & - & 10 \\
\hline Total (\%) & - & - & - & - & - & - & - & - & - & - & $\begin{array}{c}7 \\
10,0 \%\end{array}$ & $\begin{array}{c}18 \\
25,7 \%\end{array}$ & $\begin{array}{c}45 \\
64,3 \%\end{array}$ \\
\hline Livros de Biologia & & & & & & & & & & & & & \\
\hline $\begin{array}{l}\text { Linhares e } \\
\text { Gewandsznaj-der, } 2005\end{array}$ & 1 & $E$ & I & I & $\mathrm{C}$ & C & $E$ & 1 & $E$ & $E$ & 2 & 4 & 4 \\
\hline $\begin{array}{l}\text { Favaretto e Mercadante, } \\
2005\end{array}$ & 1 & $E$ & C & I & $\mathrm{C}$ & I & $E$ & 1 & 1 & E & 2 & $\begin{array}{l}3 \\
1\end{array}$ & $\begin{array}{l}5 \\
9\end{array}$ \\
\hline Laurence, 2005 & I & $\mathrm{E}$ & I & 1 & 1 & I & I & I & I & I & & & \\
\hline $\begin{array}{l}\text { Silva Junior e } \\
\text { Sasson, } 2005\end{array}$ & $E$ & $E$ & I & I & $\mathrm{C}$ & C & $E$ & 1 & I & 1 & 2 & 3 & 5 \\
\hline Amabis e Martho, 2004 & $E$ & $\mathrm{E}$ & 1 & I & $\mathrm{C}$ & $\mathrm{C}$ & $E$ & I & E & $E$ & 2 & 5 & 3 \\
\hline Paulino, 2005 & $E$ & $E$ & I & I & $\mathrm{C}$ & $\mathrm{C}$ & $E$ & I & I & I & 2 & 3 & 5 \\
\hline Lopes e Rosso, 2005 & $E$ & $\mathrm{C}$ & I & 1 & $\mathrm{C}$ & $E$ & $E$ & I & I & I & 2 & 3 & 5 \\
\hline Frota-Pessoa, 2005 & $E$ & $E$ & $E$ & 1 & I & $\mathrm{C}$ & I & $E$ & I & E & 1 & 5 & 4 \\
\hline $\begin{array}{l}\text { Adolfo; Crozetta e Lago, } \\
2005\end{array}$ & 1 & $\mathrm{E}$ & I & 1 & I & $E$ & I & I & I & 1 & - & 2 & 8 \\
\hline Total (\%) & - & - & - & - & - & - & - & - & - & - & $\begin{array}{c}13 \\
14,5 \%\end{array}$ & $\begin{array}{c}29 \\
32,2 \%\end{array}$ & $\begin{array}{c}48 \\
53,3 \%\end{array}$ \\
\hline
\end{tabular}

"C: Informações corretas. ${ }^{* *} E$ : Informações erradas. ${ }^{* * *}$ I: Informações incompletas ou não citou.

Fonte: Tabela elaborada pelos próprios autores.

Essa linguagem imprópria, associada aos erros científicos apontados, promove o conhecimento deturpado da caracterização das leishmanioses e prejudica a coparticipação de professores e alunos no enfrentamento desse problema de saúde.

As informações divulgadas em tais materiais sobre a LTA e a LV não são de grande utilidade para professores e alunos conhecedores ou não das doenças. A maioria dos conhecimentos gerados com a leitura de tal conteúdo não se relaciona à experiência direta dos estudantes, nem é aplicável à prevenção das enfermidades, restringindo-se a uma ênfase memorizadora. As doenças não são problematizadas nos livros didáticos, portanto os textos não fomentam, nos leitores, reflexões críticas sobre sua ocorrência no país e na realidade local.

Reafirma-se, como Schall (2010), que o PNLD e PNLEM são imprescindíveis para: a promoção da qualidade do ensino, a cientificidade, o aprimoramento e compromisso social dos livros didáticos. O conteúdo das leishmanioses presente nos livros analisados merece a atenção dos especialistas de tais programas, pesquisadores e educadores do Ensino Básico 
França, V. H.; Margonari, C.; Schall, V. T.

envolvidos nessa área de conhecimento. É de grande importância a revisão das informações errôneas, o preenchimento das lacunas de informação e a ampliação das reflexões sociopolíticas associadas à permanência dos agravos para se fomentar uma apropriação adequada sobre as leishmanioses por educadores e educandos, e promover uma educação em saúde dentro e fora da aula, de modo consciente, científico, sustentável e participativo.

Tendo-se em conta a literatura da área de educação em saúde e de ensino da saúde como tema transversal nas escolas, como recomendam os Parâmetros Curriculares Nacionais, percebe-se que incluir a saúde em livros de ciência tem sido um equívoco. Constata-se que o conteúdo, em geral, é superficial e inadequado. Isso remete à proposição de que a saúde possa se tornar um volume específico dentre os livros didáticos, no qual o tratamento dos temas possa estar afinado com a transdisciplinaridade exigida, os compromissos com a reflexão sobre a realidade e o entrelaçamento da saúde coletiva com a formação cidadã.

\section{Referências}

ADOLFO, A.; CROZETTA, M.; LAGO, S. Biologia: volume único: Ensino Médio. 2. ed. São Paulo: IBEP, 2005.

AMABIS, J. M.; MARTHO, G. R. Biologia: biologia dos organismos. 2. ed. São Paulo: Moderna, 2004. v. 2.

ANDRADE, M. H. P. et al. Ciência e vida: seres vivos, funções vitais e energia - $\sigma^{a}$ série. Belo Horizonte: Dimensão, 2006.

BARROS, C.; PAUlinO, W. R. Ciências: os seres vivos - 6 $6^{\text {a }}$ série. São Paulo: Ática, 2006.

BATISTA, M. V. A.; CUNHA, M. M. S.; CÂNDIDO, A. L. Análise do tema virologia em livros didáticos de biologia do Ensino Médio. Ensaio: Pesquisa em Educação em

Ciências, Belo Horizonte, v. 12, n. 1, p. 145-158, 2010.

BENCHIMOL, J. L.; SILVA, A. F. C. Ferrovias, doenças e medicina tropical no Brasil da Primeira República. História, Ciência, Saúde - Manguinhos, Rio de Janeiro, v. 5, n. 3, p. 719-762, 2008.

BORGES, B. K. A. et al. Avaliação do nível de conhecimento e de atitudes preventivas da população sobre a leishmaniose visceral em Belo Horizonte, Minas Gerais, Brasil.

Cadernos de Saúde Pública, Rio de Janeiro, v. 24, n. 4, p. 777-784, 2008.

BORTOLOZZO, S.; MALUHY, S. Série link da ciência: ciências, $6^{a}$ série - livro do professor. 2. ed. São Paulo: Escala Educacional, 2005.

BRAGA, S. A. M. et al. Construindo consciências: ciências, $5^{a}$ série. São Paulo: Scipione, 2006. (Ação e pesquisa em educação em ciências).

BRASIL. Ministério da Educação. Biologia: catálogo do Programa Nacional do Livro para o Ensino Médio - PNLEM 2009. Brasília: MEC, 2008.

MEC, 2007.

Ministério da Educação. Guia de livros didáticos PNLD 2008: ciências. Brasília: 
Análise do conteúdo das leishmanioses ...

Ministério da Educação. Livro didático: Histórico. 2010. Disponível em: <http:// www.fnde.gov.br/index.php/pnld-historico>. Acesso em: 21 out. 2010.

Ministério da Saúde e da Agricultura, Pecuária e Abastecimento. Nota de esclarecimento sobre as vacinas antileishmaniose visceral canina registradas no MAPA. Brasília: MAPA, 2009a. Disponível em: <http://portal.saude.gov.br/portal/ arquivos/pdf/leismaniosevisceral_nota_esclarecimento27052009.pdf $>$. Acesso em: 24 jun. 2010.

. Ministério da Saúde. Secretaria de Atenção à Saúde. Vigilância em saúde: zoonoses. Brasília: Ministério da Saúde, 2009b. (Série B: textos básicos de saúde. Cadernos de atenção básica, n. 22). Disponível em: <http://bvsms.saude.gov.br/bvs/publicacoes/ vigilancia_saude_zoonoses_p1.pdf>. Acesso em: 25 mar. 2010.

- Ministério da Saúde. Secretaria de Vigilância em Saúde. Departamento de Vigilância Epidemiológica. Guia de vigilância epidemiológica. 7. ed. Brasília: Ministério da Saúde, 2009c. (Série A: normas e manuais técnicos). Disponível em: <http:// portal.saude.gov.br/portal/arquivos/pdf/gve_7ed_web_atual.pdf $>$. Acesso em: 26 mar. 2010.

Ministério da Saúde. Sistema de Informação de Agravos de Notificação SINAN. Tabulação de Dados (TABNET). 2011. Disponível em: < http:// dtr2004.saude.gov.br/sinanweb/index.php>. Acesso em: 20 abr. 2011.

COSTA, A. Ciências e interação: $6^{a}$ série. Curitiba: Positivo, 2006.

DANTAS-TORRES, F. The role of dogs as reservoirs of Leishmania parasites, with emphasis on Leishmania (Leishmania) infantum and Leishmania (Viannia) braziliensis.

Veterinary Parasitology, v.149, n.3-4, p.139-146, 2007.

FAVARETTO, J. A.; MERCADANTE, C. Biologia: volume único. São Paulo: Moderna, 2005.

FIGUEIREDO, F. B. et al. Avaliação sorológica para detecção de anticorpos anti-Leishmania em cães e gatos no bairro de Santa Rita de Cássia, Município de Barra Mansa, Estado do Rio de Janeiro. Revista da Sociedade Brasileira de Medicina Tropical, Brasília, v. 42, n. 2, p. 141-145, 2009.

FRACALANZA, H.; AMARAL, I. A.; GOUVEIA, M. S. F. Está no livro? In: $\mathbf{O}$ ensino de ciências no primeiro grau. São Paulo: Atual, 1986. p. 25-45.

FROTA-PESSOA, O. Biologia. São Paulo: Scipione, 2005. v. 2.

GEWANDSZNAJDER, F. Ciências: a vida na Terra, 6a série. São Paulo: Ática, 2006.

GOWDAK, D.; MARTINS, E. Ciências: novo pensar, $5^{a}$ série ( $6^{\circ}$ ano). 2. ed. São Paulo: FTD, 2006.

LAURENCE, J. Biologia: Ensino Médio, volume único. São Paulo: Nova Geração, 2005.

LINHARES, S.; GEWANDSZNAJDER, F. Biologia: volume único. São Paulo: Ática, 2005. 
França, V. H.; Margonari, C.; Schall, V. T.

LOPES, S.; ROSSO, S. Biologia: volume único. São Paulo: Saraiva, 2005.

LUZ, Z. M. P. et al. Evaluation of informative materials on leishmaniasis distributed in Brazil: criteria and basis for the production and improvement of health education materials. Cadernos de Saúde Pública, Rio de Janeiro, v. 19, n. 2, p. 561-569, 2003.

MAGALHÃES, D. F. et al. Dissemination of information on visceral leishmaniasis from schoolchildren to their families: a sustainable model for controlling the diasease. Cadernos de Saúde Pública, Rio de Janeiro, v. 25, n. 7, p. 1642-1646, 2009.

MASSUNARI, G. K. et al. A serological and molecular investigation of American cutaneous leishmaniasis in dogs, three years after an outbreak in the Northwest of Paraná State, Brazil. Cadernos de Saúde Pública, Rio de Janeiro, v. 25, n. 1, p. 97-104, 2009.

PAULINO, W. R. Biologia: seres vivos - fisiologia. São Paulo: Ática, 2005. v. 2.

PIMENTA, D. N.; LEANDRO, A. M. S.; SCHALL, V. T. Experiências de desenvolvimento e avaliação de materiais educativos sobre saúde: abordagens sócio-históricas e contribuições da antropologia visual. In: MONTEIRO, S.; VARGAS, E. (Org.). Educação, comunicação e tecnologia educacional: interfaces com o campo da saúde. Rio de Janeiro: Fiocruz, 2006. p. 87-112.

REIS, D. C. et al. Health education and social representation: an experience with the control of tegumentary leishmaniasis in an endemic area in Minas Gerais, Brazil. Cadernos de Saúde Pública, Rio de Janeiro, v. 22, n. 11, p. 2301-2310, 2006.

REITHINGER, R; ESPINOZA, J. C.; DAVIES, C. R. The transmission dynamics of canine american cutaneous Leishmaniasis in Huánuco, Peru. American Journal of Tropical Medicine and Hygiene, v. 69, n. 5, p. 473-480, 2003.

SCHALL, V. T. Educação e divulgação científica sobre mosluscos de importância médica: breve análise de materiais informativos sobre esquistossomose. In: ENCONTRO BRASILEIRO DE MALACOLOGIA, 19., 2010, Rio de Janeiro. Anais... Rio de Janeiro, 2010. p. 391-403.

SCHALL, V. T.; DINIZ, M. C. P. Information and education in Schistosomiasis control: an analysis of the situation in the state of Minas Gerais, Brazil. Memórias do Instituto Oswaldo Cruz, Rio de Janeiro, v. 96, supl., p. 35-43, 2001.

SECRETARIA DE VIGILÂNCIA EM SAÚDE. Relatório final. II Fórum de discussão sobre o tratamento da Leishmaniose Visceral Canina (LVC). Brasília, 01 a 02 out. de 2009. Disponível em: http://portal.saude.gov.br/portal/arquivos/pdf/

ii_forum_tratamento_relatorio_final_07_10_2009.pdf>. Acesso em: 26 jun. 2010.

SILVA JÚNIOR, C.; SASSON, S. Biologia: seres vivos, estrutura e função $-2^{a}$ série. 8. ed. São Paulo: Saraiva, 2005. v. 2.

UCHÔA, C. M. A. et al. Educação em saúde: ensinando sobre a leishmaniose tegumentar americana. Cadernos de Saúde Pública, Rio de Janeiro, v. 20, n. 4, p. 935-941, 2004.

Artigo recebido em 20/10/2010. Aceito em 10/01/2011. 